\title{
Coğrafi Sosyo-Ekonomik Mahrumiyetin ve Hava Kirleticilerinin Bebek Doğum Ă̆ırlığı Üzerindeki Etkisi
}

\author{
Impacts of Geospatial Socio-Economic Deprivation and Air Pollutants on Infant Birth Weight
}

\author{
Nur H. ORAK ${ }^{1}$ \\ ${ }^{1}$ Çevre Mühendisliği Bölümü, Düzce Üniversitesi, Düzce, Türkiye
}

$\ddot{O} z$

Klasik çevresel sağlık risk tahmin yöntemleri, insan-çevre sistemlerinin döngüselliğine çözüm getirmede ve çevresel kirletici değişkenlerinin insan sağlığı üzerindeki olası etkilerinin incelenmesinde yetersiz kalmaktadır. Bu çalışmada Bayesian yöntemleri kullanarak nitrojen dioksit $\left(\mathrm{NO}_{2}\right)$ maruziyeti, partikül madde (PM), sosyoekonomik mahrumiyet ve bebek doğum ağırlığı arasındaki ilişkinin New York şehri örneği üzerinde araştırılması hedeflenmiştir. Epidemiyolojide $\mathrm{NO}_{2}$ ve $\mathrm{PM}_{2.5}$ maruziyetinin olası karıştırıcı etkenler (ör. vücut kitle indeksi) üzerindeki etkilerini göz önüne alabilmek için, ve $\mathrm{NO}_{2}, \mathrm{PM}_{2.5}$ ve değişkenlerin (ör. sosyoekonomik mahrumiyet) teorik etkileri arasında iki

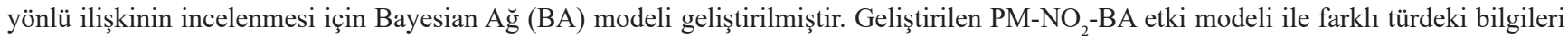
biraraya getirerek risk analizi gerçekleştirilmiş̧tir. Bu makalede sunulan modelleme yaklaşımı halk sağlı̆ına etki eden risk faktörleri arasındaki doğrusal olmayan ilişkinin değerlendirilmesi konusunda önemli katkıda bulunacaktır. Düşük Vücut Kitle Indeksine (VKI) sahip annelerin hava kirleticilerine maruziyeti ve buna bağlı olarak bebek doğum ağıllı̆̆ riskinin etkilendiği gözlenmiştir. Normal VKI'ne sahip annenin yüksek $\mathrm{NO}_{2}$ konsantrasyonuna maruziyeti sonucunda düşük doğum riski \%7 iken düşük VKI'ne sahip annenin yüksek $\mathrm{NO}_{2}$ kirliliğine maruz kalması sonucunda bu risk \%36'ya çıkmaktadır. Farklı sosyo-ekonomik mahrumiyet indeksine (SMI) ait vakalar kirleticilere maruziyet sonucunda farklı risklerle karşılaşmaktadır. $\mathrm{NO}_{2}$ maruziyetine benzer olarak $\mathrm{PM}_{2.5}$ maruziyeti düşük SMI'da yüksek risk (\%27) oluştururken daha yüksek indekse sahip grupta bu riskin azaldığı elde edilmiştir.

Anahtar Kelimeler: Çevresel istatistik, risk analizi, maruziyet-sağlı ilişkisi, halk sağlı̆̆ı, hava kirliliği, sosyoekonomik mahrumiyet

\begin{abstract}
Conventional environmental health risk estimation methods are insufficient to solve the cyclicity of human-environmental systems and to examine the possible effects of environmental pollutant variables on human health. In this study, it is aimed to investigate the relationship between nitrogen dioxide $\left(\mathrm{NO}_{2}\right)$ exposure, particulate matter (PM) exposure, socioeconomic deprivation and infant birth weight by using Bayesian methods on the New York City example. In order to consider the effects of $\mathrm{NO}_{2}$ and $\mathrm{PM}_{2.5}$ exposure on possible confounding factors in epidemiology, and to investigate the two-way relationship between theoretical effects of $\mathrm{NO}_{2}, \mathrm{PM}_{2.5}$ and variables (e.g. socioeconomic deprivation), Bayesian Network (BN) model has been developed. Risk analysis was carried out by combining different types of information based on literature knowledge and data. The proposed modeling approach presented in this article will make a significant contribution to assessing the nonlinear relationship between risk factors affecting public health. It was observed that mothers with Low Body Mass Index (BMI) were exposed to air pollutants and consequently the risk of infant birth weight was affected. While the risk of low birth is $7 \%$ as a result of exposure to high $\mathrm{NO}_{2}$ concentration of the mother with normal BMI, this risk increases to $36 \%$ as a result of the exposure of the mother with low BMI to high $\mathrm{NO}_{2}$ pollution. Cases of different socio-economic deprivation index (SMI) face different risks as a result of exposure to pollutants. Similar to $\mathrm{NO}_{2}$ exposure, $\mathrm{PM}_{2.5}$ exposure poses a high risk (27\%) in low SMI, whereas this risk decreases in the higher index group.
\end{abstract}

Keywords: Environmental statistics environmental risk analysis, exposure-health relationship, public health, air pollution, socioeconomic deprivation 


\section{GİRIŞ̧}

Çevresel sağlık araştırmalarında sosyo-ekonomik etkenlerin ve çevresel kirleticilere maruziyetin entegre edilme ihtiyacı uzun süredir bilinmektedir [1, 2]. Aynı zamanda günümüzde gebelik sürecinde hava kirleticilerine maruziyetin olumsuz etkilerini inceleyen araştırma sayısı artmaktadır [3]. Birçok literatür çalışması hava kirliliğinin doğum sürecini ve sonuçlarını olumsuz etkilediğini, buna sebep olan biyolojik mekanizmayı ve sistematik oksidatif stres etkenlerini ortaya koymaktadır [4]. Ancak az sayıda çalışma bu korelasyon ile ilişkili sosyo-ekonomik etkenleri incelemektedir. Bunun sebebi kirleticilere maruziyetin tahmin yöntemleri veya ölçüm hatası [5] gibi farklı ispat aşamalarında belirsizliklerin olmasıdır. Ayrıca, karıştırıcı etkenlerin analiz eksikliği de bu tutarsızlığa neden olmaktadır. Mevcut çalışmalar arasında ortak amaçlardan biri sosyo-ekonomik mahrumiyet ile coğrafi kirlenme maruziyeti arasındaki korelasyonun etkin bir şekilde incelenmesidir [6]. Bireysel sosyo-ekonomik düzeyin (SED) dikkate alındığı birçok çalışma, coğrafi mahrumiyetin hamilelik sonuçlarına olumsuz etki ettiğini göstermektedir [7]. Ancak, bu çalışmaların çok azı hava kirleticilerine maruziyetin ve gebelik gelişimi sonuçları arasındaki diferansiyel ilişkiyi sosyo-ekonomik düzlemde incelemiştir. Bu çalışma kapsamında Bayesian yöntemleri kullanılarak sosyo-ekonomik etkenler, hava kirliliği parametleri ve doğum ağırlığı arasındaki doğrusal olmayan ilişki olasılıksal olarak incelenmiştir.

Hızlı ve düzensiz şehirleşme hava kirleticileri ile insan sağlığı arasındaki doğrusal olmayan ilişkinin incelenmesini kritik hale getirmiştir. Tıp ve çevre bilimlerinin uyguladığ yöntemler sınırlı olmakla birlikte, çevresel boyutun analizinde yetersiz kalmaktadır. Bu çalışmada örnek bir durum üzerinden çevresel ve sağllksal etkenleri entegre edecek istatistiksel bir yöntem geliştirilmesi hedeflenmiştir. Hava kirleticilerinin halk sağlığı üzerinde uzun süreli kritik etkileri bulunmaktadır. Bu risk ile ilişkili etkilerin en aza indirgenebilmesi için öncelikle oluşma sürecinin ve etkenler arasındaki korelasyonun tespiti gerekmektedir. Sosyo-ekonomik düzeyin tanımlanması ve hesaplanmasında birçok farklı görüş bulunmaktadır. Temel etkenler arasında rrk, eğitim seviyesi ve gelir düzeyi sayılabilir. Ancak her çalışmada SED'e etki eden değişkenler farklıdır, bu nedenle fikir birliği sağlayacak bir tespit metodu önermek bugüne kadar mümkün olmamıştır. SED değişkenlerinin önemi ve risk oluşumuna katkısı senaryo bazında değişmektedir. Bu problem holistik bir yaklaşımın gerekliliğini göstermektedir.

Çevre sağlığı araştırmalarında kimyasal ve kimyasal olmayan etkenlerin insan sağlığı üzerine olan birleşik etkisine olan ilgi uzun bir süredir artmaktadır $[1,2,8,9]$. Yeni araştırma sonuçları kronik psikososyal stresin, kirleticilerin insan sağlığ ğunu bir takım epidemiyolojik ve toksikolojik kanıtlar ile ortaya koymaktadır $[10,11]$. Araştırmacıların sosyal ve fiziksel çevre arasındaki ilişkiyi anlayabilmesi için yeni yöntemlerin geliştirilmesine ihtiyaç duyulmaktadır. Psikososyal stres genel olarak sosyal stres faktörlerine (olay, durum, fiziksel veya psikolojik bir etken ile karşılaşılması) maruziyet sonucu gelişir. Bireylerin kaldırabileceğinin ötesinde stres faktörüne düzenli olarak maruz kalması sonucunda stres kronik hale gelir. Kronik psikososyal stres olumsuz duygu durumları ile ilişkilidir, bu durum immün, endokrin, ve metabolik fonksiyonlara etki eder [12]. Bu fizyolojik değişimler bireylerin kimyasal maruziyetlere (örn. kirleticiler, patojenler) olan tepkisine etki edebilir ve bu grupların birçok hastalığa olan maruziyet riskini artırabilir [13]. Bunun bir sonucu, kronik olarak sosyal stres faktörlerine maruz kalan birey ve toplumlar çevresel kirleticilerin olumsuz sağlık etkilerine daha hassas olabilir [14]. Stres faktörlerinin ölçümü öncelikli olarak bireysel anketlere veya stresli olayların tahmini için kullanılan biomarker verisine [14], stres oluşumuna sebep olabilecek durumlara [15], ve akıl sağlı̆̆ına etki eden kronik stes faktörlerine bağlıdır [16].

Kronik psikososyal stresin değerlendirilmesine odaklanan birçok epidemiyolojik çalışma bireysel seviyede stresi ölçemediğinden toplumsal indikatörleri kullanmaktadır (suç oranı, fakirlik seviyesi, muhit güvenliği, finansal stres gibi). Ancak her bireyin toplumsal stres faktörlerine karşı vereceği tepki farklıdır. Sosyal ve çevresel etkenlerin birleşik sonuçlarını inceleyen birçok epidemiyolojik çalışma SED ve demografik ölçümleri kullanmaktadır. Bunun bir sonucu olarak SED indikatörlerinin sosyal ve psikososyal stres maruziyetini ifade etmede yeterli olması konusunda belirsizlik doğmaktadır. Çok sayıda araştırma bölgesel mahrumiyetin ve SED'in doğum sonuçlarına olumsuz etki ettiğini göstermektedir [17]. Ancak bu çalışmalardan pek azı hava kirleticilerine maruziyet ile bebek doğum ağırlığ 1 arasındaki ilişkiyi incelemiştir.

$\mathrm{Bu}$ çalışmada gebelik sürecinde $\mathrm{NO}_{2}$, partikül madde $\mathrm{PM}_{2.5}$ maruziyeti ve coğrafi sosyo-ekonomik mahrumiyetin bebek gelişimine etkisini incelemek için istatistiksel bir yöntem geliştirilmesi hedeflenmiştir. Bu yöntem tıbbi bilimlerde hasta durum analizinin gerçekçi bir şekilde yapılmasında kullanılabilecektir. Bu entegre yaklaşım hava kirleticilerinin ve farklı SED değişkenlerinin kümülatif etkisini değerlendirmeyi hedeflemektedir.

$\mathrm{Bu}$ çalışmada test edilmesi ve cevaplanması planlanan hipotez ve soruların başlıcaları: Ayrı ayrı ve birleşik olarak $\mathrm{NO}_{2}$ ve $\mathrm{PM}_{2.5}$ 'in hangi konsantrasyon seviyeleri doğum 
ağırlığı üzerinde en yüksek riski oluşturmaktadır, değiş̧kenler (doğum ağırlı̆̆ı, annenin eğitim seviyesi, sağlık güvencesi, gibi) ve stres faktörleri arasındaki olasılıksal ilişki nedir, hangi senaryolar en yüksek riski oluşturur, bu etkenler ile ilgili olarak hangi anne adayı grubu hamilelik sonucunda en yüksek düşük riski ile karşı karşıyadır.

\section{MATERYAL VE YÖNTEM}

Gebelik sürecinde $\mathrm{NO}_{2}, \mathrm{PM}_{2.5}$ maruziyeti ve coğrafi sosyo-ekonomik mahrumiyetin bebek gelişimine etkisini incelemek için detaylı veriye ihtiyaç duyulmaktadır. Bu araştırmanın gerçekleştirilebilmesi için ABD'deki New York Şehri örnek olarak incelenmiştir. Bu şehrin seçilmesinin nedeni gerekli veri bankasının bulunmasıdır. Bu çalışmada Shmool ve diğ. (2015) [18] tarafindan raporlanan ve 2008-2010 yılları arasında dört mevsim süresince New York City Community Air Survey (NYCCAS) tarafindan toplanan yüksek çözünürlüklü coğrafi hava kirliliği verisi ve 2008-2010 yılları arasında New York Şehri hastane doğum kayıtlarını $(\mathrm{n}=243,853)$ özetleyen sonuçlar kullanılarak (Tablo 1) Koşullu Olasılık Tabloları (KOT) oluşturulmuştur. Buradaki amaç mekansal mahrumiyetin tanımlanabilmesi için doğum sonuçlarıyla ilişkili coğrafi tabanlı değişkenlerin kategorize edilmesidir.

$\mathrm{Bu}$ çalışmada kullanılan değişkenler: doğum ağırlı̆̆ı, annenin eğitim seviyesi, sağlı güvencesi durumu, ırk, annenin yaşı, doğum öncesi vücut kitle indeksi, gebelik süresince sağlık hizmeti alma durumu, toplam gerçekleştirdiği doğum sayıs1, gestasyonel yaş (hafta), yıl, konutsal bölgedeki $\mathrm{NO}_{2}$ konsantrasyonu (ppb), konutsal bölgedeki $\mathrm{PM}_{2.5}$ konsantrasyonudur $\left(\mu \mathrm{g} / \mathrm{m}^{3}\right)$.

Sosyo-ekonomik mahrumiyet indeksi (SMI) referans olarak kullanılan Shmool ve diğ. (2015) çalışmasına bağlı olarak modellenmiştir. Referans çalışmanın komposit indeksin hesaplanmasında baz aldığı yaklaşım Messer ve diğ. (2006) [19] çalışmasında belirtilen coğrafi tabanlı mahrumiyet indeks hesabıdır. Bu indeksin amacı şehrin farklı bölgelerindeki heterojen paternleri yeni bir jeoistatistik yaklaşım ile kategorize etmektir.

Bayesian modelleri GeNIe (Graphical Network Interface) programı ile geliştirilmiştir. GeNIe son yirmi yılda geliştirilen Bayesian tabanlı bir network programıdır [20]. Bayesian Ağları 1980'lerin sonlarında değişkenler arasındaki olasılık ilişkisini anlamak için olasılıklı bağımlılık modellerini yönlendirilmiş asiklik grafiklerle (DAG) görselleştirmek için geliştirilmiştir [21, 22]. BA'lar güçlü karar verme araçlarıdır ve diğer modelleme yaklaşımlarına kıyasla nispeten basittir [23]. Değişkenler arasındaki bağlantıların karakterizasyonu, hem nicel hem de nitel bilgilerin kullanılmasına izin verecek şekilde deterministikten ziyade, tipik olarak olasılıksaldır. KOT'lar üst hücrelerdeki olası her bir durum kombinasyonu için alt hücredeki her olası durumun olasılığını verir. Bayes kuralı (Denk. 1) ağdaki her bir düğümün inanç olasılığını sürekli olarak günceller [24]:

$$
p(X=x \mid Y=y)=\frac{p(X=x, Y=y)}{p(Y=y)}=\frac{p(X=x) p(Y=y \mid X=x)}{\sum_{x \prime} p\left(X=x^{\prime}\right) p\left(Y=y \mid X=x^{\prime}\right)}
$$

Burada X olasıllı̆ını hesaplamak istediğimiz olay, $\mathrm{Y}$ ise $X$ ile ilgili olan yeni kantlardır. İncelenen senaryoda $X$ ve Y'nin aldığ 1 değerler $\mathrm{x}$ ve $\mathrm{y}$ olarak belirtilmiştir. $\mathrm{p}(\mathrm{X} \mid \mathrm{Y})$ posterior olarak adlandırılır, bu bizim tahmin etmeye çalıştığımız koşullu değerdir. $\mathrm{p}(\mathrm{Y} \mid \mathrm{X})$ ilk hipotezimizi gözönüne aldığımızda yeni kanıtların gözlenme olasılığıdır. İlk olarak konsept model oluşturulmuştur. Konsept model iki önemli aşamadan oluşmaktadır: ağ değişkenlerinin belirlenmesi ve bu değişkenleri kullanarak model iskeletinin (etki diagramı) oluşturulması. Bayesian Ağ Modelleri sebep-sonuç ilişkisini etki diagramları üzerinden tanımladığı için bu aşama model oluşturmanın önemli bir aşamasıdır. Konsept model oluşturma konusunda birçok farklı yaklaşım bulunmaktadır. Bu çalışmada benimsenen yaklaşım uzman görüşü ile veri kaynaklı elde edilen bilginin birleştirilmesidir. Buna hibrid model de denilebilir. Veri kaynaklı etkileşim bilgilerinin elde edilmesi konusunda birçok farklı algoritma kullanılmıştır. Bunlar arasında Bayesian Search, PC, Essential Graph Search, Greedy Thick Thinning, Tree Augmented Naive Bayes (TAN), Augmented Naive Bayes, ve Naive Bayes bulunmaktadır. Modelin bu aşamasında birçok iterasyon adımı gerçekleştirilmiştir.

Etki diagramı oluşturulduktan sonra Bayesian Ağ modelindeki her bir hücre için KOT'lar referans çalışmaya göre tahmin edilir, başka bir deyişle BA modelindeki her bir hücre için gerekli olan koşullu olasılık tabloları veri kaynaklı öğrenilir. Model tamamlandıktan sonra Şekil 1'de örneklendirildiği şekilde BA modeli oluşturulmuş olur. Bu model ile çeşitli senaryolar incelenerek doğum ağırlığı üzerindeki kümülatif etkisi incelenmiştir. Kirletici konstantrasyonlarının farklı risk faktörleri ile biraraya gelerek oluşturduğu doğum ağırlığı riski incelenmiştir. Bu sayede düşük yapma riski yüksek olan anne adaylarının dahil olduğu grup olasılıksal olarak belirlenmiş̦tir. 
Tablo 1. Popülasyon karakteristikleri (Shmool ve diğ. 2015 [18] çalışmasından uyarlanmıştır). Parantez içindeki değerler ilgili kategorideki hasta sayısıdır.

\begin{tabular}{|c|c|}
\hline & $\begin{array}{c}\text { Çalışma popülasyon } \\
n=\mathbf{2 4 3 , 8 5 3} \\
\end{array}$ \\
\hline Doğum ağırlığı (g) & $\%(n)$ \\
\hline$<1500$ & $0,04(88)$ \\
\hline $1500-2499$ & $2,6(6402)$ \\
\hline $2500-3999$ & $90,3(220,156)$ \\
\hline 4000 & $7,1(17,207)$ \\
\hline Anne eğitim düzeyi (yıl) & $\%(\mathrm{n})$ \\
\hline$<9$ & $8,1(19731)$ \\
\hline $9-11$ & $17,6(42819)$ \\
\hline 12 (lise) & $23,9(58286)$ \\
\hline $13-15$ & $21,9(53376)$ \\
\hline 16 (lisans) & $16,3(39793)$ \\
\hline$>16$ & $12,2(29857)$ \\
\hline \multicolumn{2}{|l|}{ Sosyal güvence } \\
\hline Evet & $61,1(149106)$ \\
\hline Hayır & $38,9(94,747)$ \\
\hline \multicolumn{2}{|l|}{ Anne irk } \\
\hline ABD doğumlu - beyaz & $19,4(47233)$ \\
\hline Yabanc1-beyaz & $9,4(22912)$ \\
\hline ABD doğumlu-siyahi & $12,0(29339)$ \\
\hline Yabanc1-siyahi & $9,8(23856)$ \\
\hline ABD doğumlu - hispanic & $12,4(30346)$ \\
\hline Yabanc1-hispanic & $21,8(53248)$ \\
\hline ABD doğumlu-Asyalı & $1,2(2899)$ \\
\hline Yabanc1-Asyalı & $14,0(34,020)$ \\
\hline Maternal (anne) yaş & $\%(\mathrm{n})$ \\
\hline$<20$ & $6,6(16108)$ \\
\hline $20-25$ & $20,8(50608)$ \\
\hline $25-30$ & $26,6(64814)$ \\
\hline $30-35$ & $26,4(64481)$ \\
\hline $35-40$ & $15,3(37246)$ \\
\hline$\geq 40$ & $4,4(10596)$ \\
\hline \multicolumn{2}{|c|}{ Doğum öncesi Vücut Kitle Indeksi (VKI) } \\
\hline$<18,5$ (düşük) & $5,5(13445)$ \\
\hline $18,5<25$ (normal) & $54,3(132442)$ \\
\hline $25<30$ (yüksek) & $23,7(57842)$ \\
\hline$\geq 30$ (obez) & $16,5(40124)$ \\
\hline \multicolumn{2}{|l|}{ Veri Yılı } \\
\hline \multicolumn{2}{|l|}{2007} \\
\hline \multicolumn{2}{|l|}{2008} \\
\hline \multicolumn{2}{|l|}{2009} \\
\hline \multicolumn{2}{|l|}{2010} \\
\hline Yerleşim birimine yakın ortalama $\mathrm{NO}_{2}(\mathrm{ppb})$ & $26,8(5,3)$ \\
\hline Yerleşim birimine yakın ortalama $\mathrm{PM}_{25}\left(\mu \mathrm{g} / \mathrm{m}^{3}\right)$ & $11,8(1,9)$ \\
\hline
\end{tabular}

Belirtilen bilgilere dayanarak konsept Bayesian ağ modeli Şekil 1'de gösterildiği formuyla oluşturulmuştur. BA modelinde 10 (on) adet hücre bulunmaktadır. Her bir hücre farklı sayıda kategorilere ayrılmıştır. "anne yas" hücresi 6 kategoriye (20 yaş ve altı, 20-25 yaş aralığ 1 , 25-30 yaş aralığı, 30-35 yaş aralığı, 35-40 yaş aralığı, 40 yaş ve üzeri), "anne eğitim" hücresi 8 kategoriye (9 yıldan az, 9-11 y1 aras1, 12 y1l/lise, 13-15 y1l aras1, 16 y1l/lisans, 16 yıl üzeri eğitim), "anne irk" hücresi beş kategoriye (beyaz, ABD doğumlu siyahi, ülke dışı doğumlu siyahi, hispanic, asyalı), 
"SMI" hücresi üç kategoriye $(<1,5,1,5-2,5$ aralığ1, $>2,5)$, "PM" hücresi 4 kategoriye $\left(<10 \mu \mathrm{g} / \mathrm{m}^{3}, 10-11 \mu \mathrm{g} / \mathrm{m}^{3}\right.$ aras1, $11-12 \mu \mathrm{g} / \mathrm{m}^{3}$ aras1, $\left.>12 \mu \mathrm{g} / \mathrm{m}^{3}\right)$, "NO${ }_{2}$ " hücresi dört kategoriye ( $<23 \mathrm{ppb}, 23-26 \mathrm{ppb}, 26-29 \mathrm{ppb},>29 \mathrm{ppb}$ ), “dogum oncesi VKI" hücresi dört kategoriye (zayıf, normal, aşırı kilolu, obez), hedef hücre olan "dogum araligi" hücresi dört kategoriye (<3040 g, 3040-3320 g, 3320-3625 g, >3625) ayrılmıştır.

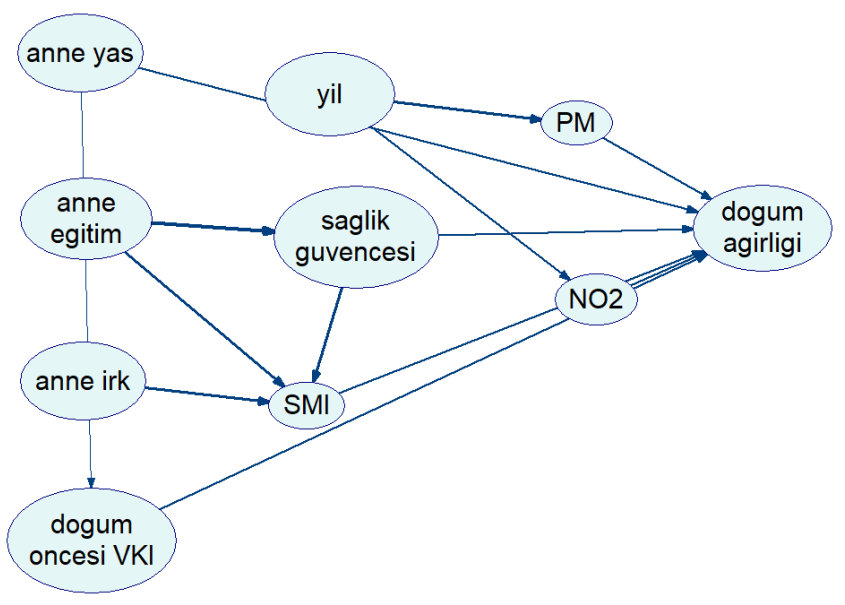

Şekil 1. Konsept Bayesian A $\breve{g}$ Modeli
İkinci adım olarak her bir hücre için referans çalışmada verilen ortalama verilere ve literatürden elde edilen bilgilere göre KOT'lar oluşturuldu. EK-Şekil 1'de her bir hücre için oluşturulan KOT'lara ait histogramlar gösterilmiştir. Şekil 3 , KOT'lar ile öğrenilmiş revize Bayesian ağ modelini göstermektedir.

Model tarafından sağlanabilecek öngörü türlerini vurgulamak için çeşitli alternatif senaryolar incelenmiştir. Bunlar:

- Farklı SMI kategorilerinin doğum ağırlığını nasıl etkilediği

- Artan hava kirletici konsantrasyonlarının $\left(\mathrm{PM}_{2.5}\right.$ ve $\mathrm{NO}_{2}$ ) doğum ağırlığını nasıl etkilediği

- Doğum öncesi annenin VKI'nin doğum ağırlığını nasıl etkilediği

$\mathrm{Bu}$ amaçla simüle edilen yirmidört senaryo Tablo 2'de listelenmiştir.

Tablo 2. Simüle edilen yirmidört senaryo (Düşük ve yüksek konsantrasyon ifadelerinin solundaki maddeler simülasyon numaralarıdır.)

\begin{tabular}{|c|c|c|c|c|c|c|c|}
\hline \multirow{5}{*}{ 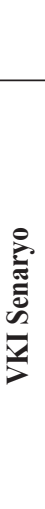 } & & \multicolumn{6}{|c|}{ SMI Senaryo } \\
\hline & & \multicolumn{2}{|c|}{ s1 } & \multicolumn{2}{|c|}{ s2 } & \multicolumn{2}{|c|}{ s3 } \\
\hline & & $\mathrm{NO}_{2}$ & PM & $\mathrm{NO}_{2}$ & PM & $\mathrm{NO}_{2}$ & PM \\
\hline & 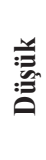 & $\begin{array}{l}\text { 1) düşük } \\
\text { s1_below_23 } \\
\text { 2) yüksek } \\
\text { s4_29_up }\end{array}$ & $\begin{array}{l}\text { 13) düşük } \\
\text { s1_below_10 } \\
\text { 14) yüksek } \\
\text { s4_12_up }\end{array}$ & $\begin{array}{l}\text { 5) düşük } \\
\text { s1_below_23 } \\
\text { 6) yüksek } \\
\text { s4_29_up }\end{array}$ & $\begin{array}{l}\text { 17) düşük } \\
\text { s1_below_10 } \\
\text { 18) yüksek } \\
\text { s4_12_up }\end{array}$ & $\begin{array}{l}\text { 9) düsşük } \\
\text { s1_below_23 } \\
\text { 10) yüksek } \\
\text { s4_29_up }\end{array}$ & $\begin{array}{l}\text { 21) düşük } \\
\text { s1_below_10 } \\
\text { 22) yüksek } \\
\text { s4_12_up }\end{array}$ \\
\hline & 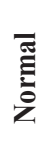 & $\begin{array}{l}\text { 3) düsşük } \\
\text { s1_below_23 } \\
\text { 4) yüksek } \\
\text { s4_29_up }\end{array}$ & $\begin{array}{l}\text { 15) düşük } \\
\text { s1_below_10 } \\
\text { 16) yüksek } \\
\text { s4_12_up }\end{array}$ & $\begin{array}{c}\text { 7) düşük } \\
\text { s1_below_23 } \\
\text { 8) yüksek } \\
\text { s4_29_up }\end{array}$ & $\begin{array}{l}\text { 19) düşük } \\
\text { s1_below_10 } \\
\text { 20) yüksek } \\
\text { s4_12_up }\end{array}$ & $\begin{array}{l}\text { 11) düşük } \\
\text { s1_below_23 } \\
\text { 12) yüksek } \\
\text { s4_29_up }\end{array}$ & $\begin{array}{l}\text { 23) düşük } \\
\text { s1_below_10 } \\
\text { 24) yüksek } \\
\text { s4_12_up }\end{array}$ \\
\hline
\end{tabular}

Model tamamlandıktan sonra hedef $(\mathrm{H})$ hücre olarak "dogum agirligi" hücresi belirlenmiştir ve modele duyarlılık testi GeNIe tarafından dahili sağlanan test özelliği ile yapılmıştır. Türev, hedef hücrenin sonsal (posterior) olasılık H'ın senaryodaki p parametresine olan ilk türevinin aldığı değerdir. Sonsal olasılık, aşağıdaki lineer rasyonel fonksiyonel form ile ifade edilir ${ }^{20}$ :

$$
H=\frac{a \times p+b}{c \times p+d}
$$

Duyarlilik analizi algoritmasi dört sabiti hesaplar; a, b, c ve d. Dört sabit hesaplandıktan sonra türevi alınarak hedef sonsal olasilık hesap edilir. Türevin formülü:

$$
D=\frac{a \times d-b \times c}{(c \times p+d)^{2}}
$$

Payda pozitif olduğundan türevin işareti p'nin tüm değerleri için sabittir ve fonksiyon monotonik veya sabittir. İlk denklemdeki p olasılığına göre p'nin bütün aralıkta değişmesiyle sonsal olasılığın ne kadar değişeceği hesaplanır. Aralık şu şekilde tanımlanmaktadır: 


$$
\begin{gathered}
p_{1}=\frac{b}{d} \\
p_{2}=\frac{a+b}{c+d}
\end{gathered}
$$

$a \times d-b \times c$ terimi hangi değerin $\left(\mathrm{p}_{1}\right.$ ve $\mathrm{p}_{2}$ 'den $)$ minimum ve maksimum olduğuna karar verir. Şekil 2 hassasiyet testinin nasıl uygulandığını göstermektedir. X-ekseni p'nin aldığı değeri, y ise $\mathrm{H}$ hedef hücresinin seçili kategorisinin aldığı sonsal olasılı̆̆ 1 göstermektedir. Yeşil grafik çizgisi çalışmada baz alınan parametrenin sonsal olasılığını, mavi çizgi ise türevini ifade etmektedir.

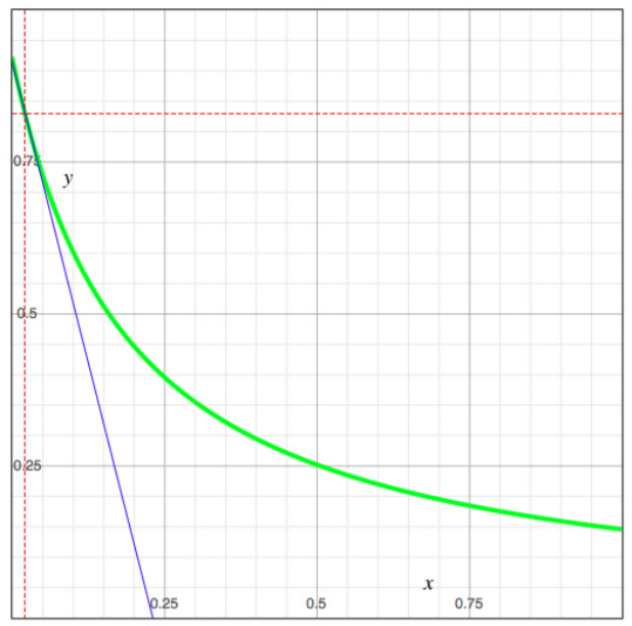

Şekil 2. GeNIe duyarlilik testi örnek [20]

\section{BULGULAR VE TARTIŞMA}

Şekil 3'te öğrenilmiş revize Bayesian Ağ modeli gösterilmiştir. Anne yas ve anne egitim değişkenlerinde normal dağılım gözlenmektedir. Düşük olarak belirtilen $2500 \mathrm{~g}$ ve altı doğum ağırlıklarının ortalama olasılığ $1 \% 5$ olarak belirtilmiştir. Bu ağ modelini baz alarak yapılan yirmidört simülasyonun ilki Şekil 4'te gösterilmiştir. Görüldüğü üzere düşük VKI'ya sahip düşük SMI'ndeki annenin 23 ppb altında $\mathrm{NO}_{2}$ kirliliğine maruz kalması durumunda bebek doğum ağırlığının düşük aralıkta olma riski \%5'ten \%13'e çıkmıştır. Karşılaştırma yapabilmek için benzer şekilde Tablo 2'de belirtilen yirmidört senaryo simüle edilmiştir.

Tablo 3 bütün senaryolar için simüle edilen sonuçları özetlemektedir. Annenin düşük VKI'ne sahip olması hava kirleticilerine maruziyetini ve buna bağlı olarak bebek doğum ağırlığı riskini etkilemektedir. S1 indeksindeki normal VKI'ne sahip annenin düşük $\mathrm{NO}_{2}$ konsantrasyonuna maruz kalması sonucunda düşük doğum ağırlığ 1 riski $\% 2$ iken, aynı şartlarda düşük VKI'ne sahip olması riski \%13'e çıkarmaktadır. VKI'nin etkisi yüksek $\mathrm{NO}_{2}$ konsantrasyonuna maruziyette daha önemli boyutta görülmektedir. Normal VKI'ne sahip annenin yüksek $\mathrm{NO}_{2}$ konsantrasyonuna maruziyeti sonucunda düşük doğum riski $\% 7$ iken düşük VKI'ne sahip annenin yüksek $\mathrm{NO}_{2}$ kirliliğine maruz kalmas1 sonucunda bu risk \%36'ya çıkmaktadır. Diğer iki SMI kategorisinde de yaklaşık olarak benzer trendler görünmektedir. S2 indeksinde yüksek $\mathrm{NO}_{2}$ maruziyeti normal

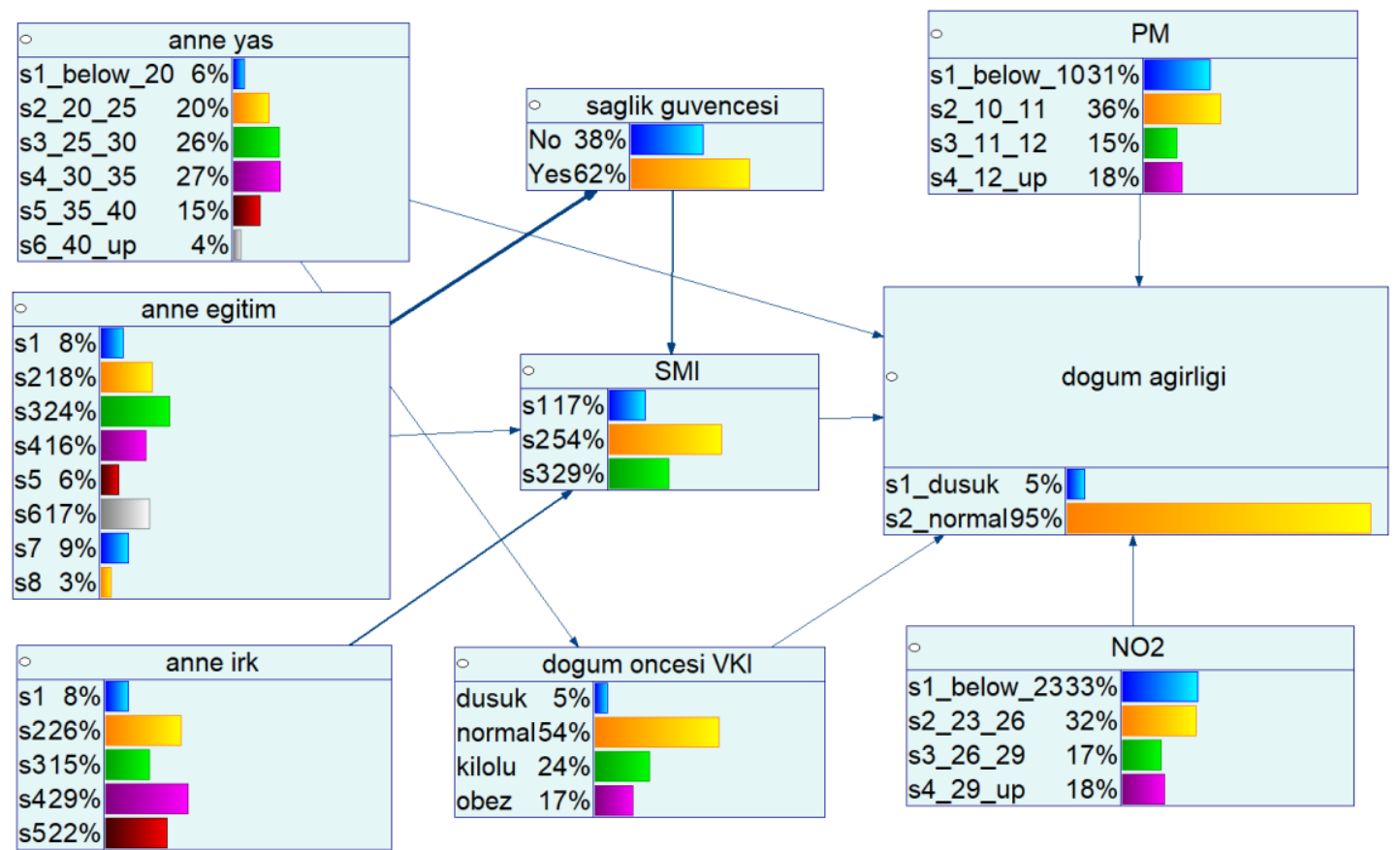

Şekil 3. Koşullu Olasılık Tabloları ile öğrenilmiş revize Bayesian Ağ Modeli (Her bir kategori için olasılıklar yüzde olarak gösterilmiştir, her bir hücrenin olasılıklarının toplamı 100 etmektedir.) 


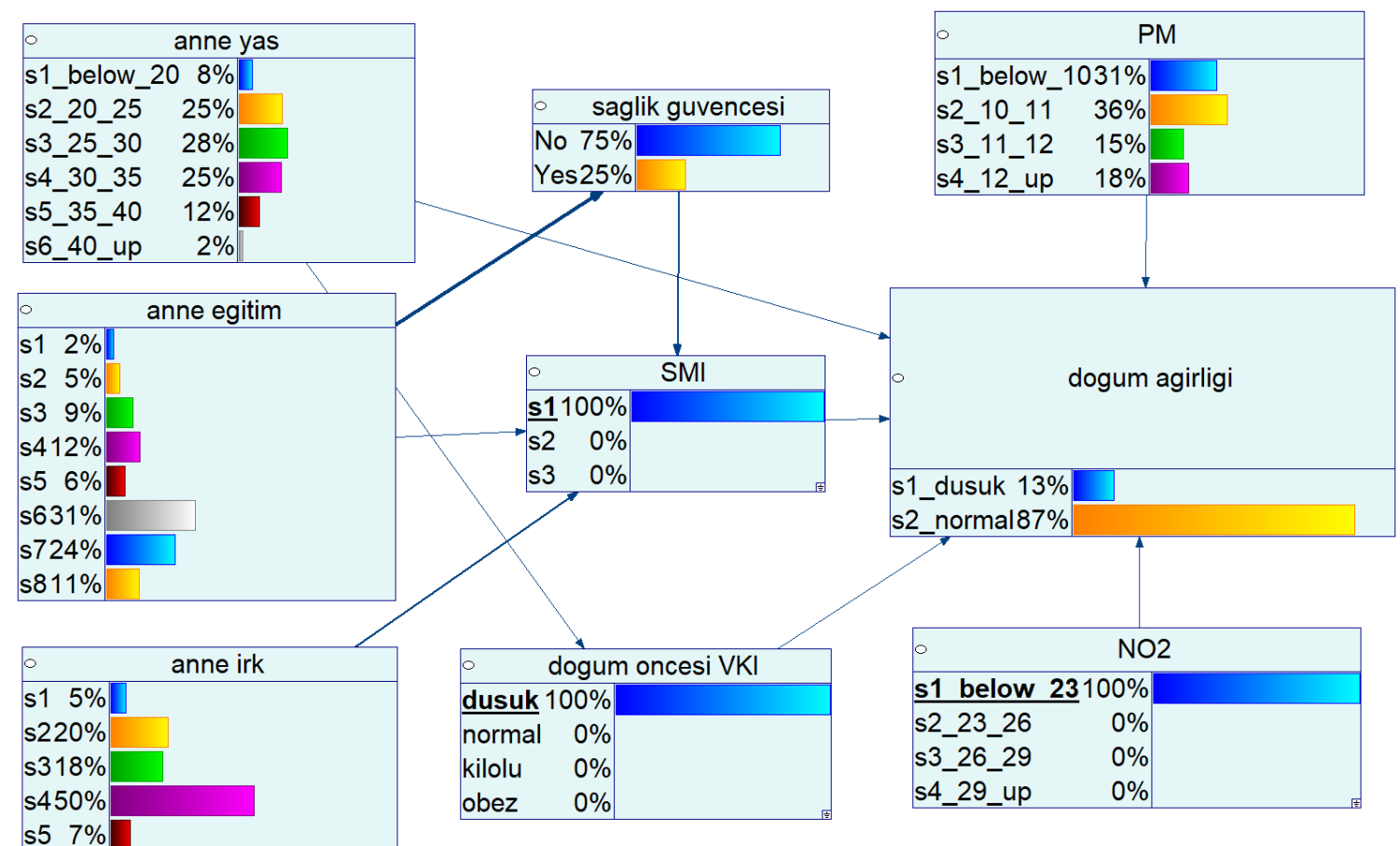

Şekil 4. Senaryo 1-Bayesian Ağ Modeli

VKI'ne sahip annede \%4 düşük doğum riski oluştururken bu risk düşük VKI'de \%17'e çıkmaktadır. S3 indeksinde de benzer bir ilişki görülmektedir. Düşük VKI'nin $\mathrm{PM}_{2.5}$ konsantrasyonuna maruziyet sonucunda normal VKI'ne sahip adaylara göre düşük doğum ağırlığı riskinin daha yüksek olduğu görülmektedir. Örneğin s1 indeksindeki bir annesin normal VKI'ya sahip olması durumunda düşük $\mathrm{PM}_{2.5}$ konsantrasyonu maruziyeti sonucunda düşük doğum ağırlığı riski \%5 iken, düşük VKI’ya sahip olması durumunda bu risk \%27'e çıkmıştır. Ancak aynı VKI'ne sahip annede artan PM maruziyetinin doğum ağırlığı riskini artırdığ1 gözlenmemiştir. Farklı SMI kategorilerini karşılaştıracak olursak farklı kirleticilere maruziyet ve farklı VKI kategorisine aidiyet etkileri farklılaştırmaktadır, diğer bir deyişle tek bir trend gözlenmemiştir. Örneğin, düşük VKI kategorisine bakacak olursak s1 indeksinde yüksek $\mathrm{NO}_{2}$ kirleticisine maruz kalma sonucu $\% 36$ risk oluşurken bu risk s2'de $\% 17$ 'ye, s3 indeksinde $\% 23$ 'e düşmektedir. Benzer trend düşük kirletici konsantrasyonunda gözlenmemiştir. Normal VKI kategorisinde ise yüksek $\mathrm{NO}_{2}$ konsantrasyonunda düşük doğum ağırlığı riski artan SMI indeksinde s1-s2 arasında azalma, s2-s3 arasında artış göstermiştir. Ancak s2 ve s3 arasındaki fark istatistiksel olarak belirgin değildir. $\mathrm{NO}_{2}$ maruziyetine benzer olarak $\mathrm{PM}_{2.5}$ maruziyeti düşük SMI'da yüksek risk (\%27) oluştururken daha yüksek indekse sahip grupta bu riskin azaldığı ancak s3'de aynı kaldığı elde edilmiştir. Benzer ilişki yüksek kirletici konsantrasyonunda da elde edilmiştir.

Tablo 3. Yirmidört senaryo için simülasyon sonucunda elde edilen düşük doğum ağırlığı olasıklıkları (Tablo 2'de belirtilen herbir senaryo numarasının yanında yüzde olarak düşük doğum riski belirtilmiştir)

\begin{tabular}{|c|c|c|c|c|c|c|c|}
\hline & & \multicolumn{6}{|c|}{ SMI Senaryo } \\
\hline & & \multicolumn{2}{|c|}{ s1 } & \multicolumn{2}{|c|}{ s2 } & \multicolumn{2}{|c|}{ s3 } \\
\hline \multirow{3}{*}{ 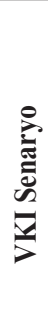 } & & $\mathrm{NO}_{2}$ & $\mathbf{P M}_{2.5}$ & $\mathrm{NO}_{2}$ & $\mathbf{P M}_{2.5}$ & $\mathrm{NO}_{2}$ & $\mathbf{P M}_{2.5}$ \\
\hline & Düşük & $\begin{array}{l}\text { 1) } \% 13 \\
\text { 2) } \% 36\end{array}$ & $\begin{array}{l}\text { 13) } \% 27 \\
\text { 14) } \% 18\end{array}$ & $\begin{array}{l}\text { 5) } \% 10 \\
\text { 6) } \% 17\end{array}$ & $\begin{array}{l}\text { 17) } \% 16 \\
\text { 18) } \% 13\end{array}$ & $\begin{array}{c}\text { 9) } \% 31 \\
\text { 10) } \% 23\end{array}$ & $\begin{array}{l}21) \% 27 \\
22) \% 31\end{array}$ \\
\hline & Normal & $\begin{array}{l}\text { 3) } \% 2 \\
\text { 4) } \% 7\end{array}$ & $\begin{array}{l}\text { 15) } \% 5 \\
16) \% 3\end{array}$ & $\begin{array}{l}\text { 7) } \% 3 \\
\text { 8) } \% 4\end{array}$ & $\begin{array}{l}\text { 19) } \% 5 \\
\text { 20) } \% 2\end{array}$ & $\begin{array}{l}\text { 11) } \% 8 \\
\text { 12) } \% 8\end{array}$ & $\begin{array}{l}\text { 23) } \% 4 \\
\text { 24) } \% 9\end{array}$ \\
\hline
\end{tabular}


Şekil 5'te görüldüğü gibi düșük SMI indeksindeki en genç anne kategorisi yüksek $\mathrm{NO}_{2}$ kirliliğine maruz kaldığında en yüksek doğum ağırlığı riskini göstermektedir. Annenin yaş1 20'nin altına düştüğünde kümülatif düşük doğum ağırlığı riski \%61'e çıkmaktadır. Aynı şartlarda annenin obez aralığına çıkması durumunda risk neredeyse aynı kalmakta (\%60) ancak normal ve kilolu aralığına düşmesi durumunda risk $\% 45$ 'e gerilemektedir. VKI'nın hava kirleticilerinden etkilenme mekanizmasına ve sonuç olarak doğum ağırlığı riskiyle olan ilişkisi önemlidir. Ayrıca aynı şartlara sahip annenin s3 kategorisine dahil olması durumunda \%61'lik risk \%17'e gerilemektedir. Bu sonuç sosyal mahrumiyet indeksinin yüksek kirleticilere maruz kalınsa dahili dolaylı oluşturduğu şartlardan dolayı düşük doğum ağırlığı riskini önemli ölçüde pozitif doğrultuda etkilediğini göstermektedir.

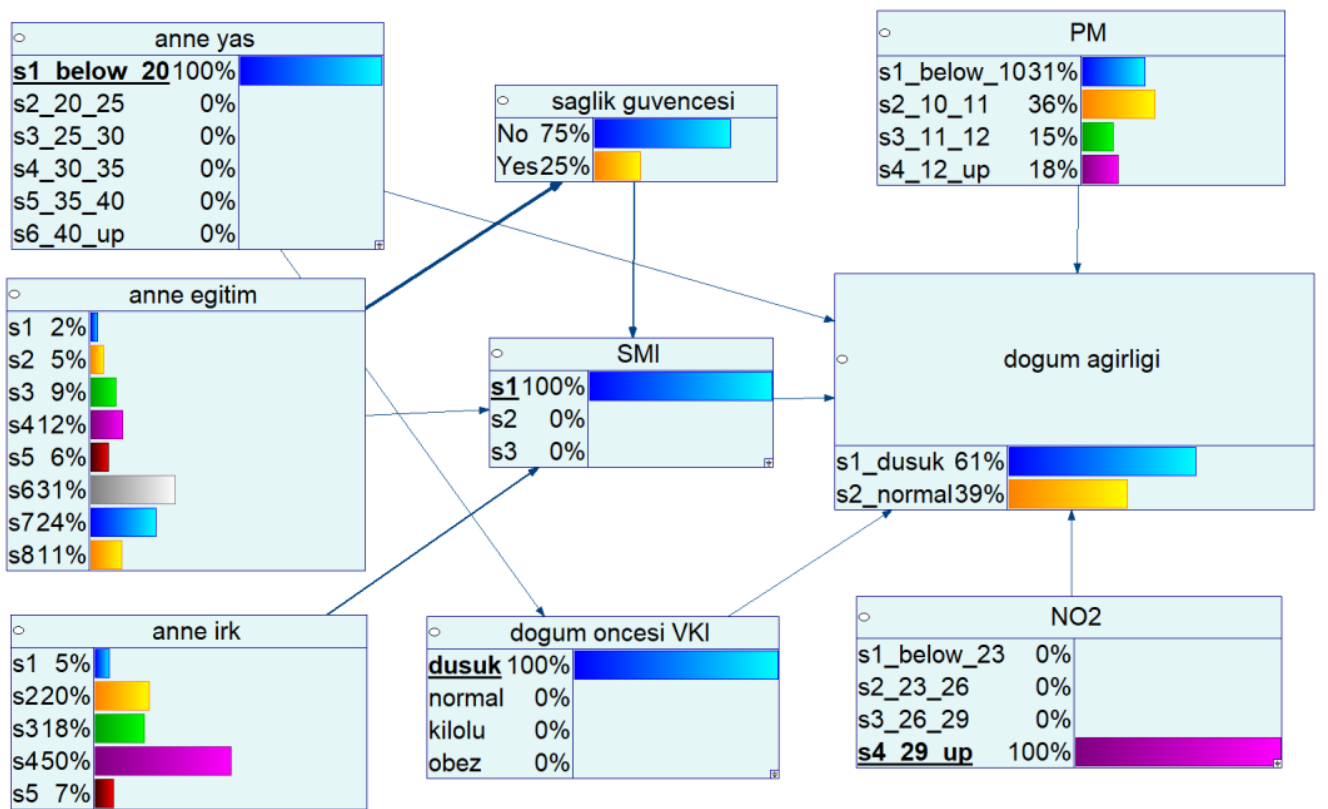

Şekil 5. Senaryo: Anne yas: <20, SMI: s1, doğum öncesi VKI: düşük, NO2: >29 ppb

$\mathrm{Bu}$ çalışmada duyarlılık analizi ile geliştirilen Bayesian modelin hedef hücresine etki eden en önemli değişkenler tespit edilmiştir. Ancak araştırmanın doğası gereği bir takım kısıtlamalar bulunmaktadır. Referans alınan çalışmada yalnızca bir bebeğe hamile, sigara içmeyen, 37-42 haftayı tamamlayan doğumlar veri olarak kabul edilmiştir. Ayrıca anne adaylarının gündelik yaşam tarzlarıyla ilgili hiçbir ölçüm kullanılmamıştır. Anne adaylarının hamilelik süresince ikamet değiştirmediği varsayılmıştır.

Şekil 6'da hedef hücre olan dogum agirligi'na etki eden hücrelerin duyarlılık derecesi gösterilmiştir. En koyu kırmızı en güçlü ilişkiyi, en açık kırmızı tonu en zayıf ilişkiyi temsil etmektedir. Hiçbir senaryo belirtilmeyen ve KOT'larının öğrenildiği bu ham modelde doğum ağırlığının duyarlılı̆g 1 en fazla anne yaşına ve hava kirleticilerine maruziyete bağlıdır.

Şekil 7'de hassasiyet testi sonucunda elde edilen tornado diyagramları gösterilmektedir. Şekil 7a'da hedef hücre için sonsal olasılık aralığı görülmektedir. Minimum ve maksimum değerler seçilen senaryoya bağlı olarak değişmektedir. Diyagram en duyarlı değişkenden en az duyarlı değişkene doğru sıralanmaktadır. Bar rengi hedef hücredeki değişimin hangi yönde olduğunu göstermektedir; kırmızı negatif, yeşil pozitif değişimi belirtmektedir. Yöntem bölümünde açıklanan $\mathrm{a}, \mathrm{b}, \mathrm{c}$ ve d katsayılarına bağlı olarak hesaplanan türev geliştirilen ağın numerik parametrelerinin ne kadar net olduğu konusunda bilgi verir. Eğer parametre p'nin türevi büyükse $p$ değerindeki küçük değişiklikler bile hedef hücrenin sonsalında büyük değişiklikler olmasına neden olabilir. Eğer türevi küçükse, parametredeki büyük değişiklikler sonsalda çok küçük değişikliklere sebep olacă̆ının işaretçisidir. Dusuk doğum ağırlığı kategorisi en fazla düşük $\mathrm{PM}_{2.5}$ konsantrasyonlarından, normal ve çok yüksek $\mathrm{NO}_{2}$ konsantrasyonundan etkilenmektedir. Hava kirletici konsantrasyonlarını takip eden en hassas değişken annenin 20 yaşın altında olma kategorisidir. Benzer trend normal doğum ağırlı̆̆ı kategorisi için de geçerlidir (Şekil 7b). 


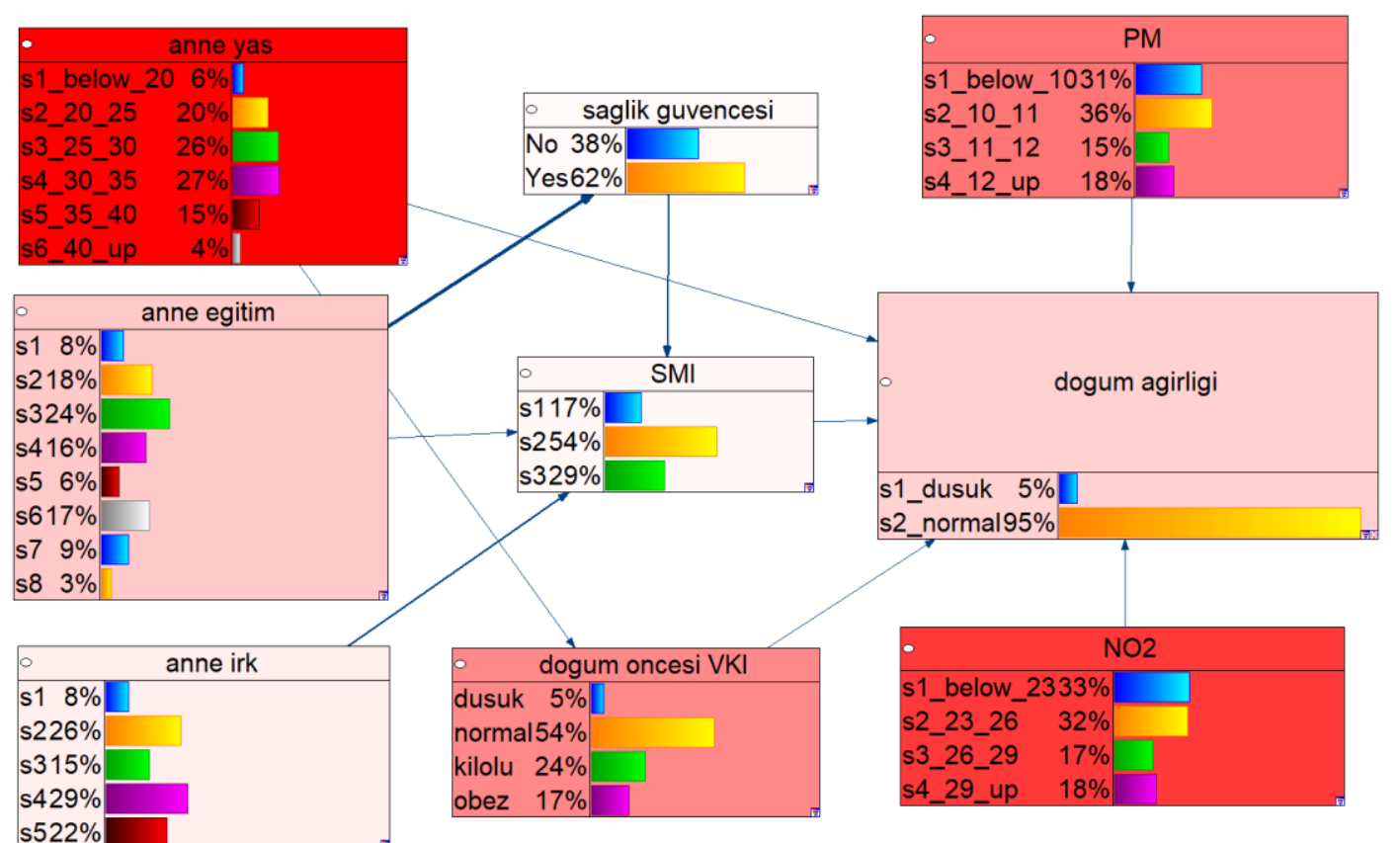

Şekil 6: Öğrenilmiş Bayesian A ̆g Modeli duyarlılık testi
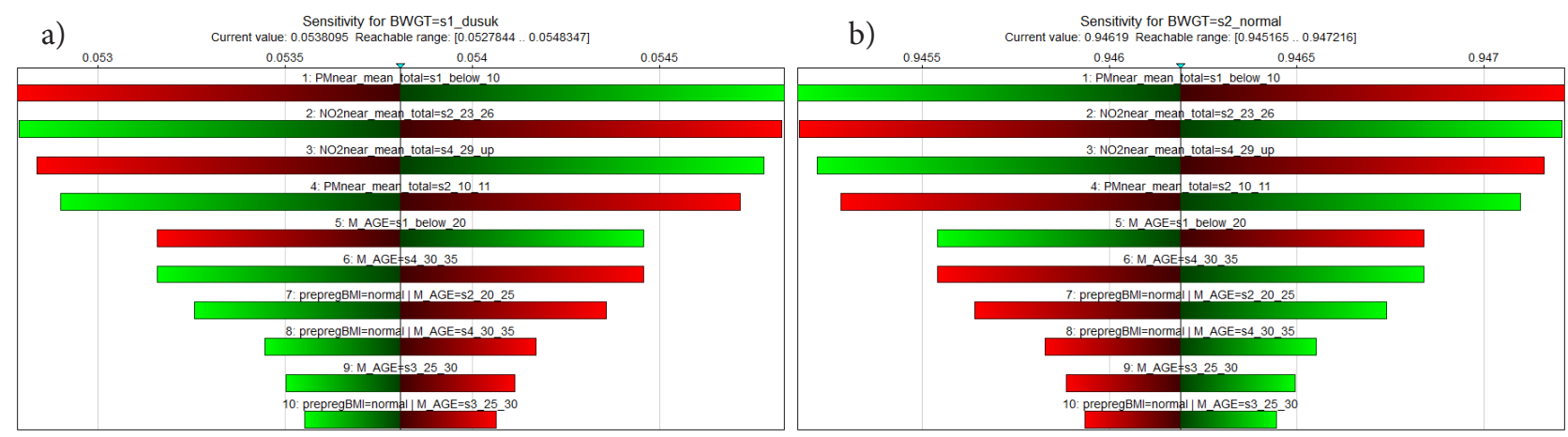

Şekil 7. Öğrenilmiş Bayesian Ağ Modeli Tornado Diyagramı

\section{SONUÇ}

Mevcut teknolojik gelişmeler yüksek çözünürlüklü veri teminini mümkün kılmıştır. Ancak veri analizi konusunda benimsenen klasik istatistiksel yöntemler veriden öğrenebileceğimiz bilgiyi kısıtlamaktadır. Tıbbi bilimlerde çevresel kirleticilerin halk sağlı̆ğ üzerindeki etkisini inceleyen bilimsel gruplar verilerin değerlendirmesi ve değişkenlerin kümülatif etkisini inceleme konusunda zorluk yaşamaktadır. Bu zorluklar ve belirsizlikler halk sağlığını koruma amaçlı etkin mevzuat değişikliklerinin yapılmasını engellemektedir. Bu çalışmada halk sağlığına etki eden risk faktörleri arasındaki doğrusal olmayan ilişkinin değerlendirmesi konusunda yeni bir yöntem sunulmuştur. Geleneksel yaklaşım olan değişkenler arasındaki ikili ilişkilerin değerlendirilmesinden farklı olarak risk faktörleri arasındaki ilişkiler ağ analizi ile incelenmiştir. Örnek olarak seçilen New York şehri hava kalitesi $\left(\mathrm{PM}_{2.5}\right.$ ve $\mathrm{NO}_{2}$ konsantrasyonları), sosyoekonomik mahrumiyet ve doğum ağırlığı arasındaki ilişki olasılıksal olarak incelenmiştir. Yirmidört farklı vaka senaryosu oluşturularak meydana gelebilecek risk seviyeleri karşılaştırılmıştır. Bebek doğum ağırlığına hava kirleticilerinin, annenin yaşının ve doğum öncesi VKI'sının önemli etkide bulunduğu gösterilmiştir. VKI'nin etkisi yüksek $\mathrm{NO}_{2}$ konsantrasyonuna maruziyette daha önemli boyutta görülmektedir. Ayrıca annenin dahil olduğu SMI'nın hava kirleticilerine olan maruziyeti ve bunun sonucunda doğum ağırlığına etki ettiği gösterilmiştir. Düşük VKI kategorisine bakacak olursak s1 indeksinde yüksek $\mathrm{NO}_{2}$ kirleticisine maruz kalma sonucu \%36 risk oluşurken bu risk s2'de \%17'ye, s3 indeksinde \%23'e düşmektedir. Bu çalışmadan elde edilen sonuçların halk sağlığı-çevresel risk analizi alanlarına birçok önemli katkısı bulunacaktır. Ayrıca bu çalışma kapsamında 
geliştirilen holistik değerlendirme çerçevesi farklı çevresel risk senaryolarına uygulanarak çok sayıda risk faktörü ve değişken aynı anda değerlendirilebilir.

\section{Teşekkür}

$\mathrm{Bu}$ araştırma kamu, ticari veya kar amacı gütmeyen sektörlerdeki finansman kuruluşlarından özel bir fon almamıştır. Bu makalede geliştirilen modeller, BayesFusion, LLC, http://www.bayesfusion.com/ adresinden akademik araştırma kullanımı için ücretsiz olan GeNIe Modeler kullanılarak oluşturulmuştur.

\section{KAYNAKÇA}

[1] Gee, G.C. and D.C. Payne-Sturges, Environmental health disparities: A framework integrating psychosocial and environmental concepts. Environmental Health Perspectives, 2004. 112(17): p. 1645-1653.

[2] Morello-Frosch, R. and E.D. Shenassa, The environmental "Riskscape" and social inequality: Implications for explaining maternal and child health disparities. Environmental Health Perspectives, 2006. 114(8): p. 1150-1153.

[3] Stieb, D.M., et al., Ambient air pollution, birth weight and preterm birth: a systematic review and meta-analysis. Environ Res, 2012. 117: p. 100-11.

[4] Burton, G.J. and E. Jauniaux, Oxidative stress. Best Practice \& Research Clinical Obstetrics \& Gynaecology, 2011. 25(3): p. 287-299.

[5] Dadvand, P., et al., Maternal Exposure to Particulate Air Pollution and Term Birth Weight: A Multi-Country Evaluation of Effect and Heterogeneity. Environmental Health Perspectives, 2013. 121(3): p. 367-373.

[6] Tian, N., J. Xue, and T.M. Barzyk, Evaluating socioeconomic and racial differences in traffic-related metrics in the United States using a GIS approach. Journal of Exposure Science and Environmental Epidemiology, 2013. 23(2): p. 215-222.

[7] Blumenshine, P., et al., Socioeconomic Disparities in Adverse Birth Outcomes A Systematic Review. American Journal of Preventive Medicine, 2010. 39(3): p. 263-272.

[8] Nweke, O.C., et al., Symposium on Integrating the Science of Environmental Justice into Decision-Making at the Environmental Protection Agency: An Overview. American Journal of Public Health, 2011. 101: p. S19-S26.

[9] Sexton, K. and S.H. Linder, Cumulative Risk Assessment for Combined Health Effects From Chemical and Nonchemical Stressors. American Journal of Public Health, 2011. 101: p. S81-S88.

[10] Zota, A.R., E.D. Shenassa, and R. Morello-Frosch, Allostatic load amplifies the effect of blood lead levels on elevated blood pressure among middle-aged US adults: a cross-sectional study. Environmental Health, 2013. 12.
[11] Hicken, M.T., et al., Do Psychosocial Stress and Social Disadvantage Modify the Association Between Air Pollution and Blood Pressure? The Multi-Ethnic Study of Atherosclerosis. American Journal of Epidemiology, 2013. 178(10): p. 1550-1562.

[12] McEwen, B.S., Stress, adaptation, and disease - Allostasis and allostatic load, in Neuroimmunomodulation: Molecular Aspects, Integrative Systems, and Clinical Advances, S.M. McCann, et al., Editors. 1998. p. 33-44.

[13] McEwen, B.S. and T. Seeman, Protective and damaging effects of mediators of stress - Elaborating and testing the concepts of allostasis and allostatic load, in Socioeconomic Status and Health in Industrial Nations: Social, Psychological, and Biological Pathways, N.E. Adler, et al., Editors. 1999. p. 30-47.

[14] Attar, B.K., N.G. Guerra, and P.H. Tolan, Neıghborhood Disadvantage, Stressful Life Events, and Adjustment in Urban Elementary-School-Children. Journal of Clinical Child Psychology, 1994. 23(4): p. 391-400.

[15] Ross, C.E. and J. Mirowsky, Disorder and decay - The concept and measurement of perceived neighborhood disorder. Urban Affairs Review, 1999. 34(3): p. 412-432.

[16] Cohen, S., T. Kamarck, and R. Mermelstein, A Global Measure of Perceived Stress. Journal of Health and Social Behavior, 1983. 24(4): p. 385-396.

[17] Pickett, K.E. and R.G. Wilkinson, Income inequality and health: a causal review. Soc Sci Med, 2015. 128: p. 316-26.

[18] Shmool, J.L., et al., Area-level socioeconomic deprivation, nitrogen dioxide exposure, and term birth weight in New York City. Environ Res, 2015. 142: p. 624-32.

[19] Messer, L.C., et al., The development of a standardized neighborhood deprivation index. Journal of Urban Health-Bulletin of the New York Academy of Medicine, 2006. 83(6): p. 1041-1062.

[20] Bayesfusion.com. GeNIe software, available from http:// www.bayesfusion.com/ 2016 [cited 2016; Available from: software, available from http://www.bayesfusion.com/.

[21] Newton, A.C., Bayesian Belief Networks in Environmental Modeling: A Review of Recent Progress. Environmental Modelling 2009: p. 13-50.

[22] Pearl, J., Probabilistic reasoning in intelligent systems: networks of plausible inference. 1988, Los Angeles: Morgan Kaufmann Publishers.

[23] Pollino, C.A. and C. Henderson, Bayesian networks: A guide for their application in natural resource management and policy, 2010, Australian Government.

[24] Murphy, K.P., Machine Learning A Probabilistic Perspective. 2012, Cambridge, Massachusetts, London, England: The MIT Press. 